University of Nebraska - Lincoln

DigitalCommons@University of Nebraska - Lincoln

2013

\title{
A retrospective study of anxiety disorder diagnoses in the military from 2000 to 2009
}

Meghan E. Lovering

U.S. Army Research Institute of Environmental Medicine, meghan.lovering@us.army.mil

Susan P. Proctor

Boston University School of Public Health

Kristin J. Heaton

VA Boston Healthcare System

Follow this and additional works at: https://digitalcommons.unl.edu/usarmyresearch

Lovering, Meghan E.; Proctor, Susan P.; and Heaton, Kristin J., "A retrospective study of anxiety disorder diagnoses in the military from 2000 to 2009" (2013). US Army Research. 205.

https://digitalcommons.unl.edu/usarmyresearch/205

This Article is brought to you for free and open access by the U.S. Department of Defense at DigitalCommons@University of Nebraska - Lincoln. It has been accepted for inclusion in US Army Research by an authorized administrator of DigitalCommons@University of Nebraska - Lincoln. 


\title{
A retrospective study of anxiety disorder diagnoses in the military from 2000 to 2009
}

\author{
Meghan E. Lovering ${ }^{\mathrm{a}, *}$, Susan P. Proctor ${ }^{\mathrm{a}, \mathrm{b}, \mathrm{c}}$, Kristin J. Heaton ${ }^{\mathrm{a}, \mathrm{b}}$ \\ a U.S. Army Research Institute of Environmental Medicine, 42 Kansas Street, Natick, MA, USA \\ ${ }^{\mathrm{b}}$ Boston University School of Public Health, Department of Environmental Health, 715 Albany Street, Boston, MA, USA \\ ${ }^{\mathrm{c}}$ Research Service, VA Boston Healthcare System, 150 South Huntington Avenue, Boston, MA, USA
}

\section{A R T I C L E I N F O}

\section{Article history:}

Received 21 October 2011

Received in revised form 5 October 2012

Accepted 10 October 2012

\section{Keywords:}

Anxiety disorders

Military

PTSD

Rates

DMED

\begin{abstract}
A B S T R A C T
The objective of this study was to describe trends in the diagnostic rates for anxiety disorders (ADs) types in the U.S. military from 2000 to 2009. Data for the numbers of diagnosed cases for the first documented occurrence of ADs during ambulatory visits while serving in the military were obtained from the Defense Medical Epidemiology Database for all active duty service members and examined across branch of service and by gender. Results indicate that Anxiety Not Otherwise Specified (ANOS) was the most frequently diagnosed AD type in each of the 10 years between 2000 and 2009, with an average rate of 0.8 per 100 service members for first service occurrence, followed by PTSD at a rate of 0.5 out of every 100. Starting in 2002, the yearly first occurrence rates of ANOS and PTSD were significantly higher $(p<0.001)$ compared to each proceeding year, with the same pattern present among males and females separately. The majority of first occurrence AD diagnoses were diagnosed in the Army ( $47 \%$ of Anxiety NOS and 60\% of PTSD cases) compared to the other service branches (i.e., Navy, Air Force, and Marines).
\end{abstract}

(c) 2012 Elsevier Ltd. All rights reserved.

\section{Introduction}

Anxiety disorders (ADs) are among the most frequently diagnosed mental health issues in the United States today (Kessler, Berglund, et al., 2005). This class of disorders, which includes Generalized Anxiety Disorder (GAD), Panic Disorder (PD), Obsessive-Compulsive Disorder (OCD), Phobic Disorder (PD), Posttraumatic Stress Disorder (PTSD), Acute Stress (AS), and Anxiety Not Otherwise Specified (ANOS), is characterized by excessive and irrational dread of everyday situations that prevent individuals from leading healthy lives (American Psychiatric Association, 2000; American Psychological Association, 2010). ADs affect an estimated 40 million American adults, or $18 \%$ of the U.S. population, each year (Kessler, Chiu, Demler, \& Walters, 2005; National Institute of Mental Health, 2009) and account for nearly 30\% of treatmentseeking patients seen by primary care physicians (Maxmen \& Ward, 2009).

The underlying etiology of ADs is complex, involving the interplay between biological and environmental factors. Some ADs appear to have a strong hereditary link. For example, risk of

\footnotetext{
* Corresponding author at: United States Army Research Institute of Environmental Medicine, 15 Kansas Street, Building 42, Natick, MA 01760, USA. Tel.: +1 508233 5126; fax: +1 5082334195 .

E-mail addresses: meghan.lovering@us.army.mil, meghan.lovering@gmail.com (M.E. Lovering).
}

developing Panic Disorder or Obsessive-Compulsive Disorder is increased by $14 \%$ (The NIMH Genetics Workgroup, 1998) and 25\% (Maxmen \& Ward, 2009), respectively, in cases where a firstdegree relative is affected. Among monozygotic and dizygotic twins, risk for developing OCD increases to $70 \%$ and 50\%, respectively (Maxmen \& Ward, 2009). Environmental factors and intrinsic personality characteristics have also been shown to contribute to the development of many ADs. For example, traumatic life experiences have been strongly linked to the onset of stress disorders and in some cases Posttraumatic Stress Disorder (PTSD) (Davidson, 2000; National Institute of Mental Health, 2009).

Although the discrete biologic and environmental factors that determine risk for development of an $\mathrm{AD}$ have been fairly well described in the literature, differences in the occurrence of ADs across demographic subsets are less well understood. In this paper, we explore the presentation of ADs within the population of U.S. military service members, a diverse subset of the general U.S. population. While it is reasonable to assume that factors influencing the development of ADs in the civilian population would contribute to $\mathrm{AD}$ development in military populations, the unique environment in which service members live and work may contribute to increased risk for development of ADs (Hoge, Auchterlonie, \& Milliken, 2006). Over the recent decade (2000-2009), service members have been engaged in the largest sustained ground operation since the Vietnam War and may be confronted with numerous sources of stress, such as extended duty hours, heavy and often physically demanding workloads, multiple deployments and 
combat exposure, which conspire to degrade physical and psychological performance.

Significant associations have been demonstrated linking combat experiences and attrition from the military to the occurrence of mental health problems (Hoge et al., 2006). Military occupations are roughly grouped into combat or support roles and the degree to which a service member is exposed to stressors, such as deployment, restricted sleep, or combat can be influenced by the type of job he or she performs (infantry versus transportation versus medic) and where he or she performs it (in a combat zone versus at a post/base in the US). All branches of service have experienced deployment over the past decade and all have been exposed to combat-related stress.

From 1990 to 1999 , roughly 6\% of all active duty U.S. military service members per year received treatment for a mental health disorder (Hoge et al., 2002). Service members deployed to combat zones reportedly experience more mental health issues upon their return home (19.1\% for those deployed to Iraq and $11.3 \%$ for those deployed to Afghanistan) than those deployed to other locations (8.5\%) (Hoge et al., 2006). In addition, mental health hospitalizations appear to be increasing, accounting for more hospitalizations of U.S. service members in 2010 than any other major category of diagnoses (Medical Surveillance Monthly Report, 2011). Among the mental health issues experienced by military service members, anxiety disorders appear to be increasingly prevalent. ADs were ranked fourth and eighth, respectively, for bed days and medical encounters among the health care burdens attributable to various diseases and injuries for U.S. service members in 2010 (Medical Surveillance Monthly Report, 2011). One study (Riddle et al., 2007) examined the prevalence of mental disorders among the Millennium Cohort, a large epidemiologic study of U.S. military. This study found prevalence rates based on screening criteria for PSTD at $2.4 \%$, $1.0 \%$ for panic syndrome, and $2.0 \%$ for other anxiety syndromes. All reported mental disorders, excluding alcohol abuse, were found to be higher for women relative to their male counterparts.

The negative impact of ADs on individuals and society can be devastating. Symptoms such as cognitive problems (difficulty with attention and concentration, impaired memory, and trouble thinking), sensory disruption (e.g., feeling disoriented or distanced from reality, blurred vision, and hypervigilance), mood disturbance (preoccupation with vulnerability, danger, and fear), and decrements in physical performance (hypertension, insomnia, and pain) can negatively impact an individual's ability to work, maintain healthy relationships, and function optimally in day-to-day activities (Beck \& Emery, 2005). Moreover, the cost of treating anxiety disorders in the United States has been estimated at $\$ 46.6$ billion, accounting for $31.5 \%$ of mental illness costs (DuPont et al., 1996). Since 2001, the bed days attributable to mental health disorders have increased more than 3-fold (Medical Surveillance Monthly Report, 2011). In 2010 mental disorders accounted for $42.7 \%$ of all hospital bed days, more than any other morbidity category (Medical Surveillance Monthly Report, 2011). The Medical Surveillance Monthly Report (2011) also noted mental health disorders contributed 573 personyears of lost military duty due to hospitalization.

Gender also appears to play a role in the risk for anxiety disorders. Various civilian epidemiological studies have noted that women are at greater risk than men for developing an anxiety disorder (Angst \& Dobler-Mikola, 1985; Bruce, Yonkers, Otto, Eisen, \& Weisberg, 2005). Similarly, studies utilizing the National Comorbidity Survey have reported higher prevalence of Agoraphobia, Panic Disorder, GAD (Kessler et al., 1994), and PTSD (Kessler, Chiu, et al., 2005; Kessler, Sonnega, Bromet, Hughes, \& Nelson, 1995) in women compared to men. A recent review of literature pertaining to gender differences in fear and anxiety (McLean \& Anderson, 2009) concluded that women often exhibit higher levels of anxiety across their life span than males due to the interplay of biological and environmental factors, thus contributing to increased treatment seeking behaviors and higher rates for being diagnosed with an anxiety disorder.

ADs represent a significant threat to operational or mission readiness and soldier performance and are costly both in terms of human and material resources. Ultimately, a better understanding of the rates of ADs in military service members might be used to encourage and improve early detection, diagnosis, and treatment. This information can also be used to help support and refine existing programs aimed at educating service members about mental health issues and developing interventions aimed at strengthening mental and physical resilience. In this study, we describe trends in the occurrence of ADs within the U.S. military during a ten year period, from 2000 to 2009. We specifically examine the first diagnosed occurrence of ADs in military service members, or "first time occurrence” (Army Medical Surveillance Activity, 2009), across branches of service and gender groupings. The time period selected extends work by Hoge and colleagues (2002) who described rates of mental health diagnoses among U.S. military personnel in the years prior to 2000 , and permits characterization of AD diagnostic trends across a period of increasing combat exposure for all branches of military service.

\section{Materials and methods}

\subsection{Study design}

This epidemiological investigation examined preexisting medical surveillance data contained in the Defense Medical Surveillance System (DMSS), specifically within the Defense Medical Epidemiology Database version 3.6.4 (DMED), to describe the rates of first time diagnosis of ADs in active duty military personnel, across all branches of military service (Army, Navy, Air Force, and Marines) and among males and females from 2000 to 2009.

\subsection{Description of dataset}

The Army Medical Surveillance Activity (Aberdeen Proving Ground, MD) collects and analyzes medical surveillance data to be included in the DMSS. The DMED contains up-to-date records on healthcare utilization (e.g. hospitalizations and outpatient visits) and demographic data (e.g. age, rank, race, marital status, and gender) for all military personnel who have been on active duty for at least one month. The database is updated monthly by the Defense Manpower Data Center and contains records covering a ten year period, which allows for limited longitudinal assessment of military personnel and medical event data from all services (Army Medical Surveillance Activity, 2009; Hoge et al., 2002). The DMED database is accessible online at http://afhsc.army.mil/aboutDmed. Military and civilian personnel may request permission from the Armed Force Health Surveillance Center to access the remote database. The DMED application allows users to submit queries with regard to disease and injury rates in the active duty population, including specific queries of gender, race, rank, and marital status across branches of the military, within a ten year period. The user can query the database system to examine first time occurrences or all occurrences. The DMED database contains only de-identified, de-linked data, allowing researchers to look at descriptive statistics, such as means, standard deviations, and percent of population, across a selected time period.

The Standard Ambulatory Data Record (SADR) documents outpatient treatment provided to service members at military medical facilities and outsourced non-Department of Defense clinics. Diagnoses entered into these respective medical databases are recorded 
using the International Classification of Diseases, 9th Revision (ICD9) (Army Medical Surveillance Activity, 2009).

\subsection{Data selection and extraction}

We used ICD-9 codes, identified by Hoge and colleagues (2002), to characterize anxiety-related disorders in active duty military personnel. These codes and their corresponding Diagnostic and Statistical Manual of Mental Disorders, Fourth Edition (DSM-IV; 2000) labels are listed in Table 1. For those ADs with multiple ICD9 codes (e.g., Panic Disorder and Phobic Disorders) subtype codes were combined to characterize the overall rate of the disorder. As a conservative estimate of AD rates of occurrence within the military, in this study we focused specifically on first time occurrence of ADs as diagnosed during ambulatory visits. First time occurrence refers to the first diagnosed AD during a service member's military career. We chose to examine first time occurrence, rather than any/all occurrence/s, due to limitations inherent in the use of a deidentified dataset. In this format, it is not possible to link individual service members to specific encounters or across years, a factor that increases the risk of over-counting individuals who may have multiple encounters entered into the dataset for a single diagnosis. Such might be the case for individuals seen over time in an ambulatory setting for AD-related issues or for those hospitalized, since any given diagnostic code may be entered numerous times during the course of a single visit (for example, following each medical procedure performed).

Data selected for extraction were stratified and analyzed by ICD9 codes, branch of military service (Air Force, Army, Navy, and Marines) and gender groups for each year from 2000 to 2009. At the time of data extraction, 2010 data were incomplete and were therefore excluded from the study. For the purposes of this study, we classified the pre/early war time frame as inclusive of 2000-2002, with 2003-2009 describing a period of active combat operations in both Iraq and Afghanistan.

Comparison of diagnosis rates between specified years and computed risk ratios (RR) and 95\% confidence intervals (CIs), based on counts of persons with records ADs per total number of persons in the service (and subgroup) in that year, were performed following methods described in Rothman and Greenland (1998). The first time occurrence rate was calculated by the number of diagnosed cases divided by the yearly population to produce the annual rate. Rates are reported either per 100 persons per year or in percentage units. (For example, a first time occurrence rate of 5 persons per 100 persons in the population in that year is comparable to $5 \%$ ).

\section{Results}

\subsection{Description of the U.S. military population from 2000 to 2009}

A description of key demographic characteristics across the U.S. military as a whole and across individual branches of service is provided in Table 2. On average, over this 10 year period, the Army made up 36\%, the Navy $25.7 \%$, the Air Force $25.2 \%$, and the Marines $13.1 \%$ of the total U.S. military population. Over all service branches, and on average over the 10 years, $14.6 \%$ of the U.S. military population was female.

The total number of military service members (across all branches of service) with a diagnosed first time occurrence of $\mathrm{AD}$ (primary diagnosis) on ambulatory visit from 2000 to 2009 is presented in Table 1. During the study period, Anxiety NOS was the most frequently diagnosed $\mathrm{AD}$ at an average rate of $0.80 \%$ for first time occurrence. PTSD was the second most commonly diagnosed AD (0.48\%), with GAD, Acute Stress, PD, Phobic Disorder, and OCD following (average rates of $0.21 \%, 0.14 \%, 0.14 \%, 0.08 \%$, and $0.04 \%$, respectively). Together, ambulatory medical visits for ANOS and PTSD within this time period accounted for $68 \%$ of all diagnosed ADs from 2000 to 2009.

The annual first time occurrence rates of any $\mathrm{AD}$ diagnosis (prevalence rate) for each of the three years prior to the initiation of Operation Iraqi Freedom (2000-2002) were the lowest rates recorded over the ten year study period. The rates show a steady increase during the years corresponding to OEF/OIF (2003-2009), with the higher rates of all initial AD diagnoses reported in 2008 and 2009 (Fig. 1). During this period, ANOS was the most frequently diagnosed AD (1.48\% in 2009), followed by PTSD (1.03\% in 2008). GAD, Acute Stress, Phobic Disorder, and OCD rates remained relatively stable over the ten year period, while diagnosed Panic Disorder declined from 2008 to 2009.

Below we provide further description of the first time occurrence rates for the two most frequently diagnosed ADs within the study period, ANOS and PTSD.

\subsection{Anxiety Not Otherwise Specified}

Rates of ANOS diagnoses were highest for Army service members $(1.06 \%)$, followed by Air Force $(0.78 \%)$, Marines $(0.59 \%)$ and Navy $(0.56 \%)$ across the study time period (rates per 100 service members). Comparing the 2009 rate to that in 2000, there was a significant increase $(p<0.0001)$ in diagnosed ANOS $(R R=3.152$; $95 \% \mathrm{CI}: 3.065,3.242$ ). Furthermore, comparing the 2009 rate to that

Table 1

Anxiety-related ICD-9 diagnostic codes, corresponding DSM-IV diagnoses, key symptoms, and first time medical visits from 2000 to 2009.

\begin{tabular}{|c|c|c|c|}
\hline ICD-9 codes & Anxiety disorders & Symptoms & $\begin{array}{l}\text { Number of ambulatory } \\
\text { visits 2000-2009 }\end{array}$ \\
\hline 300.02 & Generalized Anxiety Disorder & $\begin{array}{l}\text { At least six months of persistent, excessive anxiety and } \\
\text { worry }\end{array}$ & 29,436 \\
\hline $\begin{array}{l}300.01 \\
300.21\end{array}$ & Panic Disorder & $\begin{array}{l}\text { Recurrent unexpected panic attacks which warrant } \\
\text { persistent concern }\end{array}$ & 21,489 \\
\hline 300.3 & Obsessive-Compulsive Disorder & $\begin{array}{l}\text { Obsessions which cause distress and/or compulsions in an } \\
\text { attempt to assuage anxiety }\end{array}$ & 5043 \\
\hline $\begin{array}{l}300.22 \\
300.23 \\
300.29\end{array}$ & Phobic Disorder & $\begin{array}{l}\text { Clinically significant anxiety triggered by exposure to a } \\
\text { feared object, environment, or social situation }\end{array}$ & 10,688 \\
\hline 309.81 & Posttraumatic Stress Disorder & $\begin{array}{l}\text { Re-experiencing of an extremely traumatic event } \\
\text { accompanied with heightened arousal and avoidance of } \\
\text { stimuli associated with the trauma }\end{array}$ & 65,487 \\
\hline 308.3 & Acute Stress & $\begin{array}{l}\text { Similar symptoms to PTSD occurring immediately after the } \\
\text { traumatic event }\end{array}$ & 18,758 \\
\hline 300.00 & Anxiety Not Otherwise Specified & $\begin{array}{l}\text { Symptoms do not meet diagnostic criteria for a specific } \\
\text { anxiety disorder, however, level of distress and anxiety is } \\
\text { impairing daily functioning }\end{array}$ & 111,308 \\
\hline
\end{tabular}

American Psychiatric Association (2000), American Psychological Association (2010), and Hoge et al. (2002). 
Table 2

Demographics for U.S. military service members from 2000 to 2009.

\begin{tabular}{|c|c|c|c|c|c|c|}
\hline & & Army & Navy & Air Force & Marines & Total \\
\hline \multicolumn{7}{|c|}{ Overall population } \\
\hline & \% of Pop. & $36.03 \%$ & $25.69 \%$ & $25.22 \%$ & $13.06 \%$ & $100.00 \%$ \\
\hline & Mean $^{\mathrm{a}}$ & $497,785.20$ & $355,002.40$ & $348,484.90$ & $180,463.4$ & $1,381,735.90$ \\
\hline & $\mathrm{SD}^{\mathrm{b}}$ & $24,519.11$ & $20,160.91$ & $16,306.52$ & $10,331.90$ & $21,280.14$ \\
\hline \multicolumn{7}{|l|}{ Gender } \\
\hline \multirow[t]{3}{*}{ Male } & \% of Pop. & $85.53 \%$ & $85.57 \%$ & $80.56 \%$ & $93.89 \%$ & $85.38 \%$ \\
\hline & Mean $^{\mathrm{a}}$ & $425,745.00$ & $303,790.40$ & $280,748.10$ & $169,432.90$ & $1,179,716.40$ \\
\hline & $\mathrm{SD}^{\mathrm{b}}$ & $24,460.72$ & $18,206.72$ & $13,236.82$ & 9484.00 & $16,855.74$ \\
\hline \multirow[t]{3}{*}{ Female } & \% of Pop. & $14.47 \%$ & $14.43 \%$ & $19.44 \%$ & $6.11 \%$ & $14.62 \%$ \\
\hline & Mean $^{a}$ & $72,013.00$ & $51,211.70$ & $67,736.30$ & $11,029.90$ & $201,990.90$ \\
\hline & $\mathrm{SD}^{\mathrm{b}}$ & 1831.69 & 2327.96 & 3288.86 & 858.85 & 5972.55 \\
\hline \multicolumn{7}{|l|}{ Race } \\
\hline \multirow[t]{3}{*}{ White } & \% of Pop. & $64.71 \%$ & $66.50 \%$ & $73.75 \%$ & $74.01 \%$ & $68.67 \%$ \\
\hline & Mean $^{\mathrm{a}}$ & $322,102.60$ & $236,090.80$ & $257,018.30$ & $133,565.50$ & $948,777.20$ \\
\hline & $\mathrm{SD}^{\mathrm{b}}$ & $32,218.61$ & $18,800.76$ & $12,780.81$ & $12,337.03$ & $20,467.34$ \\
\hline \multirow[t]{3}{*}{ Black } & \% of Pop. & $22.96 \%$ & $19.08 \%$ & $15.11 \%$ & $12.28 \%$ & $18.59 \%$ \\
\hline & Mean $^{\mathrm{a}}$ & $114,294.70$ & $67,747.70$ & $52,673.60$ & $22,158.90$ & $256,874.90$ \\
\hline & $\mathrm{SD}^{\mathrm{b}}$ & 8461.73 & 4871.12 & 3817.55 & 2545.23 & $18,478.92$ \\
\hline \multirow[t]{3}{*}{ Other } & \% of Pop. & $12.33 \%$ & $14.41 \%$ & $11.13 \%$ & $13.71 \%$ & $12.74 \%$ \\
\hline & Mean $^{\mathrm{a}}$ & $61,386.70$ & $51,163.00$ & $38,792.00$ & $24,737.90$ & $176,079.60$ \\
\hline & $\mathrm{SD}^{\mathrm{b}}$ & 2214.51 & 4217.79 & 2656.20 & 660.89 & 6241.92 \\
\hline \multicolumn{7}{|l|}{ Age } \\
\hline \multirow[t]{3}{*}{$<20$} & \% of Pop. & $7.43 \%$ & $7.33 \%$ & $5.56 \%$ & $14.49 \%$ & $7.85 \%$ \\
\hline & Mean $^{\mathrm{a}}$ & $37,004.60$ & $26,009.10$ & $19,366.70$ & $26,150.00$ & $108,530.40$ \\
\hline & $\mathrm{SD}^{\mathrm{b}}$ & 4260.00 & 5438.82 & 4074.59 & 856.64 & $13,215.44$ \\
\hline \multirow[t]{3}{*}{$20-24$} & \% of Pop. & $32.54 \%$ & $32.19 \%$ & $28.65 \%$ & $47.27 \%$ & $33.39 \%$ \\
\hline & Mean $^{\mathrm{a}}$ & $161,949.60$ & $114,272.60$ & $99,837.70$ & $85,301.40$ & $461,361.30$ \\
\hline & $\mathrm{SD}^{\mathrm{b}}$ & 7371.07 & 8670.98 & 8143.57 & 5935.51 & $17,870.62$ \\
\hline \multirow[t]{3}{*}{$25-29$} & \% of Pop. & $22.20 \%$ & $21.11 \%$ & $21.57 \%$ & $17.36 \%$ & $21.13 \%$ \\
\hline & Mean ${ }^{\mathrm{a}}$ & $110,460.00$ & $74,928.80$ & $75,155.80$ & $31,333.90$ & $291,938.50$ \\
\hline & $\mathrm{SD}^{\mathrm{b}}$ & $12,361.78$ & 2786.55 & 5718.96 & 3212.94 & $21,958.08$ \\
\hline \multirow[t]{3}{*}{$30-34$} & \% of Pop. & $15.28 \%$ & $14.91 \%$ & $15.45 \%$ & $9.36 \%$ & $14.46 \%$ \\
\hline & Mean ${ }^{\mathrm{a}}$ & $76,068.80$ & $52,938.90$ & $53,833.00$ & $16,891.10$ & $199,731.80$ \\
\hline & $\mathrm{SD}^{\mathrm{b}}$ & 2471.01 & 3079.31 & 2329.14 & 809.13 & 4638.65 \\
\hline \multirow[t]{3}{*}{$35-39$} & \% of Pop. & $12.64 \%$ & $13.59 \%$ & $15.42 \%$ & $6.94 \%$ & $12.84 \%$ \\
\hline & Mean $^{\mathrm{a}}$ & $62,910.20$ & $48,229.60$ & $53,748.60$ & $12,519.40$ & $177,407.80$ \\
\hline & $\mathrm{SD}^{\mathrm{b}}$ & 2833.45 & 5308.13 & 8521.99 & 539.13 & $12,637.62$ \\
\hline \multirow[t]{3}{*}{$\geq 40$} & \% of Pop. & $9.91 \%$ & $10.88 \%$ & $13.36 \%$ & $4.58 \%$ & $10.33 \%$ \\
\hline & Mean $^{\mathrm{a}}$ & $49,311.20$ & $38,617.60$ & $46,539.90$ & 8265.00 & $142,733.70$ \\
\hline & $\mathrm{SD}^{\mathrm{b}}$ & 5397.56 & 2278.35 & 3236.82 & 180.00 & 5552.33 \\
\hline
\end{tabular}

Army Medical Surveillance Center (2009).

a Numbers presented are the average number of persons in the respective service branch over each of the 10 years in the time period of interest.

b Standard deviation (SD) about the presented mean.

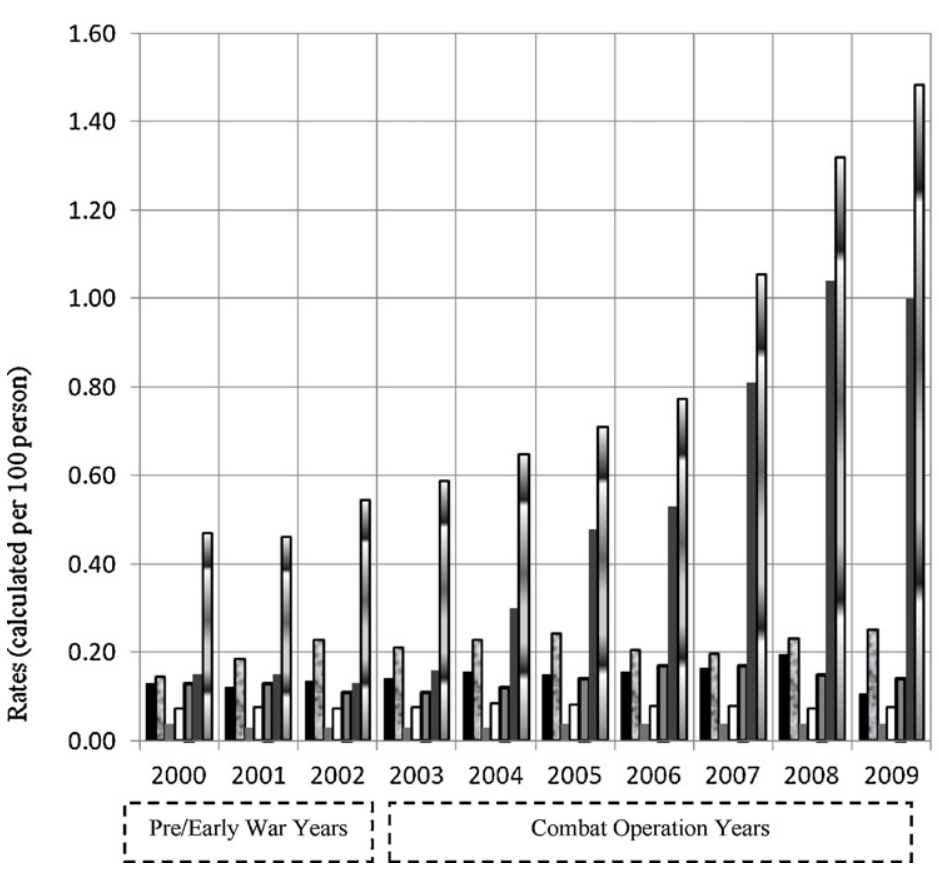

Panic Disorder
口GAD
口OCD
口Phobic Disorder
口Acute Stress
口PTSD
日ANOS
HISTORICAL TIMELINE
9/2001: September 11 th
terrorist attacks on the
United States
3/2003: US-Iraq War
Begins
6/2004: Iraqi Interim
Government Established
10/2005: 2,000th
Military death in Iraq
1/2007: US Troop
Surge; Over 160,000
troopsin Iraq
12/2007: Deadliest year
for American Troops
2/2009: President
Obama announces end
of combat in Iraq

Fig. 1. First time occurrence rate of anxiety disorders in the military (2000-2009). 
Table 3

Comparison of diagnosed anxiety rates between specified years and computed risk ratios (RR).

\begin{tabular}{rrrrrrl}
\hline & PTSD & \multicolumn{5}{c}{ ANOS } \\
\cline { 2 - 7 } & Count & RR & $95 \%$ CI & Count & RR & $95 \%$ CI \\
\hline 2000 & 2046 & & & 6394 & & \\
2001 & 2047 & 0.998 & $0.939,1.061$ & 6295 & 0.982 & $0.949,1.017$ \\
2002 & 1809 & 0.866 & $0.813,0.923$ & 7574 & 1.179 & $1.141,1.219$ \\
2003 & 2269 & 1.240 & $1.161,1.314$ & 8300 & 1.079 & $1.046,1.114$ \\
2004 & 4186 & 1.845 & $1.753,1.942$ & 9152 & 1.103 & $1.070,1.136$ \\
2005 & 6564 & 1.607 & $1.546,1.671$ & 9759 & 1.093 & $1.062,1.125$ \\
2006 & 7239 & 1.115 & $1.078,1.153$ & 10516 & 1.089 & $1.060,1.120$ \\
2007 & 11031 & 1.525 & $1.480,1.571$ & 14349 & 1.366 & $1.332,1.400$ \\
2008 & 14311 & 1.284 & $1.252,1.316$ & 18153 & 1.252 & $1.225,1.280$ \\
2009 & 13985 & 0.957 & $0.935,0.980$ & 20816 & 1.123 & $1.101,1.146$ \\
\hline
\end{tabular}

Risk ratio (RR) comparisons are between each year and its preceding year: e.g., PTSD 2005 (comparison between 2004 and 2005); 95\% CI, 95\% confidence intervals.

Note: Gray shading indicates statistically significant comparisons $(p<0.05) 95 \% \mathrm{CI}$ ranges that both are greater than and exclude 1.0 signify the rate is significantly higher than the rate in the year prior; those $95 \%$ CIs that are both less than and exclude 1 indicate the rate is significantly lower than the year prior.

in 2000, there was a significant increase $(p<0.0001)$ in diagnosed ANOS for both females ( $R R=2.33 ; 95 \% \mathrm{CI}: 2.21,2.45)$ and males $(\mathrm{RR}=3.53$; 95\% CI: 3.42, 3.65). Comparing the 2009 rate to that in 2000, there was a significant increase $(p<0.0001)$ in diagnosed ANOS for all services; Army ( $R R=5.86$; $95 \% \mathrm{CI}$ : 5.59, 6.14), Navy $(\mathrm{RR}=1.72 ; 95 \% \mathrm{CI}: 1.62,1.83)$, Air Force ( $\mathrm{RR}=1.51 ; 95 \% \mathrm{CI}: 1.43$, 1.59), and Marines ( $\mathrm{RR}=4.15 ; 95 \% \mathrm{CI}: 3.76,4.59)$. Starting in 2002, the yearly rates for the first occurrence of ANOS are significantly higher compared to each proceeding year (Table 3 ).

\subsubsection{Army}

The Army represents the largest proportion of military personnel across all branches of service, with an increase of $15.77 \%$ in total population across the ten year study period. When compared to the other three branches of service, the Army demonstrated the highest average first time occurrence rate for ANOS (1.06\%), with $47 \%$ of all first time Anxiety NOS cases. The number of soldiers with a first initial occurrence of ANOS on ambulatory visit pre/early war was 2302 compared to 6565 during the war period. Across the study time frame, Army females had higher rates of ambulatory visits for ANOS (an average rate of $1.67 \%$ per year) than their male counterparts (an average rate of $0.95 \%$ per year) (Fig. 2). As previously noted, ANOS ambulatory visits reached a peak in 2009. In 2009, Army females made up $36.7 \%$ of the females in the military, while Army males accounted for $39.3 \%$ of males in the military. During 2009, the first time occurrence rate of ANOS diagnosis was $3.21 \%$ for Army females (the highest rate by gender across all branches of the military) and $2.18 \%$ for Army males (the third highest annual rate for ANOS by gender across all branches of the military).

\subsubsection{Navy}

The Navy represents the second largest branch of military service overall, with a reported decrease in population of $10.65 \%$ across the study period. The Navy demonstrated the lowest average first time occurrence rate for ANOS, $0.56 \%$ per year. During the pre/early war period, the average ANOS count within the Navy was 1637 for first time ambulatory visit compared to 2302 during the war period. Similar to Army rates, Navy females were diagnosed at a higher rate
(1.2\%) than their male counterparts (0.5\%). Over the ten years evaluated, female Sailors had the lowest rates of ADs of all females in the military; however, this rate was still higher than ANOS rates for males across all military branches (Fig. 2).

\subsubsection{Air Force}

The AF is the third largest branch of service, with a population that decreased across the study period by $6.53 \%$. Rates of first occurrence of ANOS from 2000 to 2009 were $0.78 \%$ for AF personnel, the second highest rate across branches of service. Prior to 2003, the average ANOS count was 2271 for first time ambulatory visit compared to 2914 during the war. When looking at ANOS by gender, female AF personnel were diagnosed at a higher average rate per year (1.5\%) than male AF personnel (0.63\%) (Fig. 2).

\subsubsection{Marines}

From 2000 to 2009 the population of the Marines, the branch of service with the smallest population, increased by $18.48 \%$. Prior to 2003, the number of Marines diagnosed with a first time occurrence of ANOS was 544 compared to 1226 during the war period (2003-2009). The average first time ANOS diagnosis rate per year was $0.59 \%$ during the ten year study period. Female Marines were diagnosed with ANOS at a higher rate per year (1.5\%) than their male counterparts ( $0.51 \%$ ) across the study period, and had the third highest average ANOS rate of ambulatory visits across all branches of service.

\subsection{Posttraumatic Stress Disorder}

PTSD was the second most frequent first time occurrence AD diagnosis during the reported study period (25\% of all cases) across all branches of service. The average rates of PTSD diagnoses were highest for Army service members (0.77\%), followed by Marines (0.56\%), Navy (0.24\%), and Air Force (0.18\%) and across the study time period. Rates of PTSD by service branch and gender are described in Fig. 3. Comparing the 2009 rate to that in 2000 , there was a significant increase $(p<0.0001)$ in diagnosed PTSD (RR=6.619; 95\% CI: 6.319, 6.933). Furthermore, comparing the 2009 rate to that in 2000 , there was a significant increase $(p<0.0001)$ in diagnosed PTSD for both females $(\mathrm{RR}=1.91 ; 95 \% \mathrm{CI}$ : $1.77,2.06)$ and males ( $R R=11.3812 ; 95 \% \mathrm{CI}: 10.66,12.14)$. Comparing the 2009 rate to that in 2000 , there was a significant increase $(p<0.0001)$ in diagnosed PTSD for all services; Army $(R R=13.85$; 95\% CI: 12.80, 14.98), Navy (RR=1.82; 95\% CI: 1.66, 1.99), Air Force $(\mathrm{RR}=3.0495 \% \mathrm{CI}: 2.70,3.42)$, and Marines ( $\mathrm{RR}=7.99 ; 95 \% \mathrm{CI}: 7.00$, 9.13). As found with ANOS, starting in 2002, the rates for the first occurrence of PTSD are significantly higher in each subsequent year (Table 3) compared to the prior year.

\subsubsection{Army}

The majority of cases of first time PTSD diagnosis in the military across the ten year study period (60\%) were reported in Army service members. Prior to 2003, the average annual PTSD count in the Army was 655 for first time ambulatory visits compared to 5249 during the war. The average first time PTSD diagnosis rate per year was $0.77 \%$ during the ten year period. When looking at PTSD by gender, overall, Army females were diagnosed at a higher average rate than males over the ten year period. However, during the war years, Army males were diagnosed with PTSD at an average rate of $1.05 \%$ compared to Army females at $0.94 \%$ annually (Fig. 3). The highest rates of diagnosed first time occurrence PTSD were for male Soldiers in 2008 and 2009, with rates of $1.86 \%$ and $1.77 \%$, respectively. 

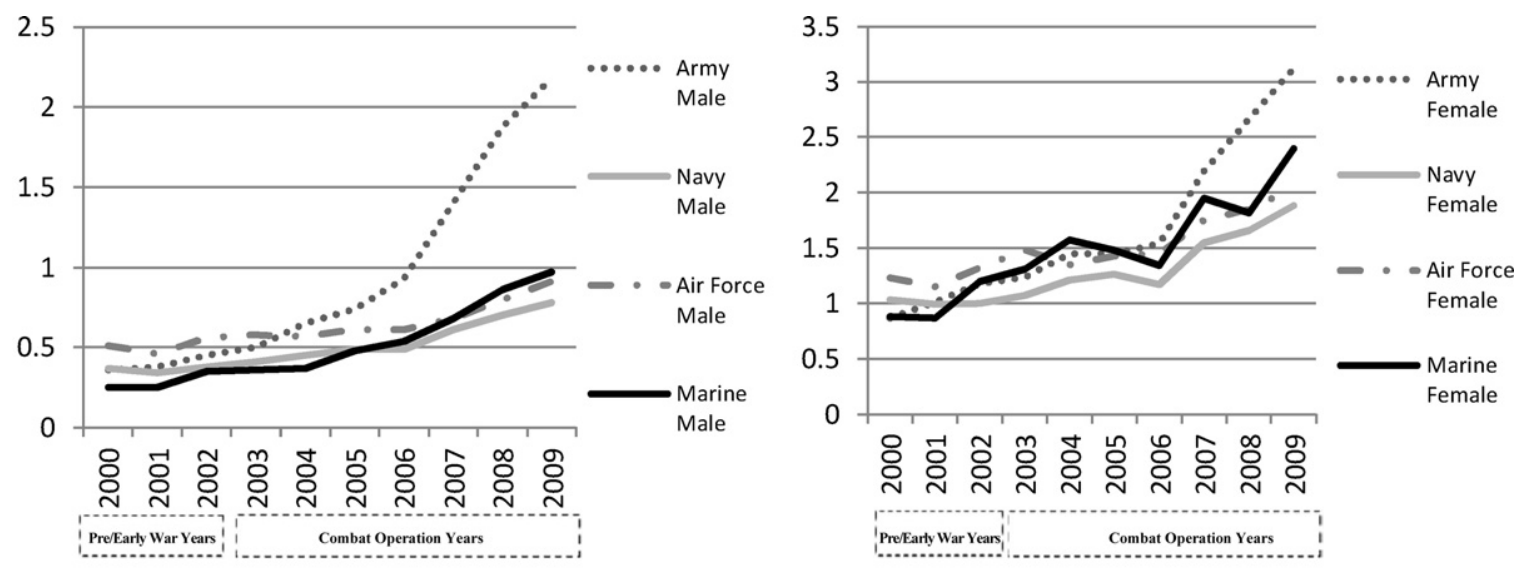

*Rates calculated per 100 person

Fig. 2. First time occurrence rates of ANOS by gender (2000-2009).


*Rates calculated per 100 person

Fig. 3. First time occurrence rates of PTSD by gender (2000-2009).

\subsubsection{Navy}

Across the four branches of service, the Navy had the third highest first time occurrence rate of PTSD during the study period. The average first time PTSD diagnosis rate per year was $0.24 \%$ during the ten year study period. In the 2 years prior to 2003, the average annual number of persons with first time occurrence PTSD in the Navy was 644 compared to 979 during the combat operations years. Female Sailors were diagnosed at a higher average rate $(0.65 \%)$ than male Sailors $(0.12 \%)$ per year (Fig. 3 ). Ambulatory visits for first time diagnosis of PTSD peaked in 2009, with Navy females and males being diagnosed at a rate of $0.78 \%$ and $0.36 \%$, respectively.

\subsubsection{Air Force}

The AF had the lowest first time occurrence rate for PTSD across all branches of service during the ten year study period $(0.18 \%)$. In the 2 years prior to 2003, the average annual number of persons with first time occurrence PTSD in the Navy was 383 compared to 767 during the combat operations years. Female AF personnel were diagnosed at a higher average rate $(0.43 \%)$ than male AF personnel $(0.14 \%)$ per year. Ambulatory visits for PTSD first time diagnosis reached a peak in 2009, with female AF personnel being diagnosed at a rate of $0.57 \%$ and males at a rate of $0.29 \%$.

\subsubsection{Marines}

Marines had the second highest first time occurrence rate of PTSD across the study period, at an average annual rate of $0.56 \%$. In the 2 years prior to 2003, the average annual number of persons with first time occurrence PTSD in the Marines was 235 compared to 1352 during the combat operations years. Female Marines were diagnosed at a higher average rate $(0.86 \%)$ than males $(0.54 \%)$ per year. The years 2008 and 2009 saw a peak in first diagnosed occurrence of PTSD. In 2008, male Marines were diagnosed with a higher first time occurrence rate (1.21\%) compared to females $(1.12 \%)$. However, in 2009 female Marines were diagnosed at a rate of $1.28 \%$, the highest of the ten years evaluated.

\section{Discussion}

The findings indicate a significant increase in first time occurrence rates of ADs as a primary disorder in ambulatory care visits in the ten year period which included the initiation of OIF/OEF. ANOS 
and PTSD represented the more common ADs diagnosed and also demonstrated the largest significant increases across all branches of service in the years following the onset of combat operations in Iraq and Afghanistan.

Although mental health outcomes can be influenced by a number of intrinsic and extrinsic factors, we chose to specifically focus on gender due to the increase of women serving in combat roles (Draude, 1995; Mulrine, 2012). Results revealed that females were diagnosed at higher rates for ANOS across all branches of service and for PTSD within the Air Force and Navy relative to their male counterparts. These results support previous research suggesting that women with and without combat experience report higher levels of stress than males with combat experience and that women with combat experience seek more assistance for medical-related issues than combat males (Tarrasch, Lurie, Yanovich, \& Moran, 2011). While female service members are utilized in combat positions, the majority of combat roles are still held by men, which might account for the higher rates of PTSD in Army and Marine males. Despite the different rates, PTSD increased for both males and females across the war period.

These results, as well as previous studies, highlight the increasing incidence of mental health disorders in the military. For example, Hoge et al. (2002) found that mental disorders were the fifth leading diagnostic category among ambulatory care visits between 1998 and 1999. In 2007, mental disorders were second only to musculoskeletal system injuries as the leading cause of ambulatory care visits (Army Medical Surveillance Activity, 2009). Between 1995 and 1999, mental disorders were reportedly the second leading cause of military hospitalizations (Hoge et al., 2002). By 2009, mental disorders exceeded pregnancy-related conditions as the leading cause of hospitalizations in the military (Army Medical Surveillance Activity, 2009).

A number of factors may have contributed to the observed increase in $\mathrm{AD}$ diagnoses, including exposure to combat, long periods of time away from family and support networks, and a heightened awareness of stress-related mental health issues within the military medical community. The commencement of OIF in March of 2003 produced an increased tempo of normal military operations and an upsurge in new deployments. Prior to September 11th 2001, there were approximately 26,000 troops stationed in the U.S. Central Command region consisting of Kuwait, Saudi Arabia and on ships in the region (Belasco, 2009). Between fiscal year 2002-2008 the number of troops rapidly increased at least 30-fold in Iraq and Afghanistan (Belasco, 2009). Deployment can be a significant source of stress, as it often entails long periods of time away from family with limited access to communication back home, in which service members might also endure potentially harsh field conditions, reduced privacy, periods of boredom, uncertainty, and potential hostile threats (Bartone, Adler, \& Vaitkus, 1998). Adler, Huffman, Bliese, and Castro (2005) found that for male soldiers, longer deployments and first-time deployments were associated with an increase in reported distress during a peacekeeping mission. Service members who experienced ground combat while deployed to Iraq and Afghanistan were significantly more likely to screen positive for PTSD post-deployment, and for those who did screen positively, were also more likely to be wounded or injured during their deployment (Hoge et al., 2004, 2006). Moreover, although women serving in the U.S. military have historically been excluded from combat-related jobs, the nature of operations in Iraq and Afghanistan may place women at higher risk for exposure to stressful combat situations (Mattocks et al., 2012). Our results documented an increase of anxiety disorders during combat years which support the work of Hoge et al. (2006) who found an elevated incidence of PTSD (almost three times higher) in the combat-deployed population than in the non-combat-deployed population but explanations for the factors contributing to these rate increases are not within the scope of this descriptive study. With many male and female soldiers deployed to combat zones, further study is warranted to understand the potential interaction between ADs, gender, and deployment-related stress.

In addition to deployment, the occupational roles service members play may be a factor in determining risk for development of ADs. Marines and Army typically provide the largest percentage of ground combat forces to military operations, while Navy and Air Force generally provide support from the air and sea. Although all military service members, regardless of occupational role or branch of service, are at risk for exposure to a variety of stressful experiences while deployed to combat zones, some military occupational roles present an elevated risk of exposure (e.g., infantry and special forces) relative to other roles (e.g., supply or maintenance)(Langley, 2006).

While there is no equivalent comparison for "first time diagnosis" in the general population, looking at diagnostic rates as an estimate reveals that the diagnosis of anxiety disorders within the military is well below those reported within the civilian population based on these results. There are a number of different factors that play into a lower diagnostic rate. It could be due to reporting trends within the military. Previous research has documented the perceived stigma associated with mental illness within the military and the under utilization of mental health services (Ben-Zeev, Corrigan, Britt, \& Langford, 2012). Due to the mental health stigma, service members may be less inclined than their civilian peers to report or seek help for mental health issues. It is also possible that the "healthy warrior effect" is contributing to the lower rates. Service members are a relatively fit group and may experience lower rates of ADs as a group overall, in comparison to the general population which includes unemployed and disabled persons (Larson, Highfill-McRoy, \& Booth-Kewley, 2008). While there could be a number of different factors at play, this study cannot determine why the rate of ADs was lower than the civilian population.

Although this study shows a significant increase in the rates of $\mathrm{ADs}$ since the start of $\mathrm{OEF} / \mathrm{OIF}$, the data examined represent cases newly diagnosed while in military service. As a result, it is unclear what proportion of these service members were seeking treatment for preexisting conditions. In addition, neither the frequency of visits related to the primary AD diagnosis nor the severity of the condition could be determined in this study given the use of a de-identified data set. Further, these findings capture only documented encounters, thus potentially under-representing the actual prevalence of $\mathrm{AD}$ in the military. Caution is advised in using electronic military health care system records that rely on ICD-9 codes as they can lead to "erroneous conclusions about incidence and prevalence" (Hoge, 2008, p. 1096) due to factors such as service members avoiding treatment for mental disorders and clinicians declining to record ICD-9 codes for mental health diagnoses.

Our results highlight an increase in AD diagnoses over time within military service members across all branches of service. Left untreated or insufficiently managed, anxiety disorders can lead to degradation in physical and mental health, personal relationships, and work performance, leaving those affected at an increased risk for serious negative health outcomes. Given the potentially devastating impact of ADs on the lives of service members, these findings suggest that heightened attention should be paid to AD screening, monitoring, and treatment within all branches of service. Previously, considerable attention has been paid to PTSD; however, these results suggest other ADs are also important to screen and monitor, specifically Anxiety NOS. Early identification and intervention are key to more efficient and effective symptom management, promote service member health and readiness, and could help mitigate long term negative health outcomes. 


\section{Acknowledgments}

The opinions or assertions contained herein are the private views of the author(s) and are not to be construed as official or as reflecting the views of the Army or the Department of Defense.

This research was supported in part by an appointment to the Postgraduate Research Participation Program at the U.S. Army Research Institute of Environmental Medicine administered by the Oak Ridge Institute for Science and Education through an interagency agreement between the U.S. Department of Energy and U.S. Army Medical Research Materiel Command (USAMRMC).

The authors would like to acknowledge MAJ Owen Hill, PhD from the Total Army Injury and Health Outcomes Database (TAIHOD) for lending his expertise to this paper.

\section{References}

Adler, A. B., Huffman, A. H., Bliese, P. D., \& Castro, C. A. (2005). The impact of deployment length and experience on the well-being of male and female soldiers. Journal of Occupational Health Psychology, 10, 121-137.

American Psychiatric Association. (2000). Diagnostic and statistical manual of mental disorders (4th ed.). Arlington, VA: American Psychiatric Association.

American Psychological Association. (2010). Anxiety disorders: the role of psychotherapy in effective treatment. Retrieved from. http://www.apa.org/ helpcenter/anxiety-treatment.aspx

Angst, J., \& Dobler-Mikola, A. (1985). The Zurich study: V. Anxiety and phobia in young adults. European Archives of Psychiatry and Neurological Sciences, 235 $171-178$.

Army Medical Surveillance Activity. (2009). Defense Medical Epidemiology Database. Retrieved from. http://afhsc.army.mil/aboutDmed

Bartone, P. T., Adler, A. B., \& Vaitkus, M. A. (1998). Dimensions of psychological stress in peacekeeping operations. Military Medicine, 163, 157-593.

Beck, A. T., \& Emery, G. (2005). Anxiety disorders and phobias: a cognitive perspective. Cambridge, MA: Basic Books.

Belasco, A. (2009). Troop levels in the Afghan and Iraq Wars, FY2001-FY2012: cost and other potential issues (CRS R40682). Washington, DC: Congressional Research Service.

Ben-Zeev, D., Corrigan, P. W., Britt, T. W., \& Langford, L. (2012). Stigma of mental illness and service use in the military. Journal of Mental Health, 21(3), 264-273.

Bruce, S. E., Yonkers, K. A., Otto, M. W., Eisen, J. L., Weisberg, R. B., Pagano, M., et al. (2005). Influence of psychiatric comorbidity on recovery and recurrence in generalized anxiety disorder, social phobia, and panic disorder: a 12-year prospective study. American Journal of Psychiatry, 162, 1179-1187.

Davidson, J. R. T. (2000). Trauma: the impact of post-traumatic stress disorder. Journal of Psychopharmacology, 14, S5-S12.

Draude, T. V. (1995). Woman in combat. Aviation, Space and Environmental Medicine, 66(12), 1207-1211.

DuPont, R. L., Rice, D. P., Miller, L. S., Shiraki, S. S., Rowland, C. R., \& Harwood, H. J. (1996). Economic costs of anxiety disorders. Anxiety, 2,4, 167-172.

Hoge, C. W. (2008). Re: "Psychiatric diagnoses in historic and contemporary military cohorts: combat deployment and the healthy warrior effect". American Journal of Epidemiology, 168, 1095-1096.
Hoge, C. W., Auchterlonie, J. L., \& Milliken, C. S. (2006). Mental health problems use of mental services, and attrition from military service after returning from deployment to Iraq or Afghanistan. Journal of the American Medical Association 295(9), 1023-1032.

Hoge, C. W., Castro, C. A., Messer, S. C., McGurk, D., Cotting, D. I., \& Koffman, R L. (2004). Combat duty in Iraq and Afghanistan, mental health problems, and barriers to care. New England Journal of Medicine, 351, 13-22.

Hoge, C. W., Lesikar, S. E., Guevara, R., Lange, J., Brundage, J. F., Engel, C. C., et al. (2002) Mental disorders among U.S. military personnel in the 1990s: association with high levels of health care utilization and early military attrition. American Journa of Psychiatry, 159, 1576-1583.

Kessler, R. C., Berglund, P., Demler, O., Jin, R., Merikangas, K. R., \& Walters, E. E. (2005). Time prevalence and age-of-onset distributions of DSM-IV disorders in the national comorbidity survey replication. Archives of General Psychiatry, 62, 593-603.

Kessler, R. C., Chiu, W. T., Demler, O., \& Walters, E. E. (2005). Prevalence, severity, and comorbidity of twelve-month DSM-IV disorders in the National Comorbidity Survey Replication (NCS-R). Archives of General Psychiatry, 62(6), 617-627.

Kessler, R. C., McGonagle, K. A., Zhao, S., Nelson, C. B., Hughes, M., Eshleman, S., et al. (1994). Lifetime and 12-month prevalence of DSM-III-R psychiatric disorders in the United States Results from the National Comorbidity Survey. Archives of General Psychiatry, 51, 8-19.

Kessler, R. C., Sonnega, A., Bromet, E., Hughes, M., \& Nelson, C. B. (1995). Posttraumatic stress disorder in the National Comorbidity Survey. Archives of General Psychiatry, 52, 1048-1060.

Langley, C. R. (2006). U.S. military comparison chart. Retrieved from. http://www. summit-academy.com/HighSchool/educational\%20planning/Docs/Military Comparison_Sheet2.pdf

Larson, G. E., Highfill-McRoy, R. M., \& Booth-Kewley, S. (2008). Psychiatric diagnoses in historic and contemporary military cohorts: combat deployment and the healthy warrior effect. American Journal of Epidemiology, 167, 1269-1276.

Mattocks, K. M., Haskell, S. G., Krebs, E. E., Justice, A. C., Yano, E. M., \& Brandt, C. (2012). Women at war: understanding how women veterans cope with combat and military sexual trauma. Social Science $\mathcal{E}^{\prime}$ Medicine, 74, 537-545.

Maxmen, J. S., \& Ward, N. G. (2009). Essential psychopathology and its treatment (3rd ed. revised for DSM-IV). New York, NY: W.W. Norton \& Company Inc.

McLean, C. P., \& Anderson, E. R. (2009). Brave men and timid women? A review of the gender differences in fear and anxiety. Clinical Psychology Review, 29, 496-505.

Medical Surveillance Monthly Report. (2011). Annual summary issue. Armed Health Forces Surveillance Center, 18(4), 1-28. Retrieved from http://afhsc.mil/ viewMSMR?file=2011/v18_n04.pdf

Mulrine, A. (2012). Women in combat: US military on verge of making it official. The Christian Science Monitor. http://www.csmonitor.com/USA/Military/ 2012/0701/Women-in-combat-US-military-on-verge-of-making-it-official Accessed October 2012

National Institute of Mental Health. (2009). Anxiety disorders (NIH Publication No. 09 3879). Washington, DC: U.S. Government Printing Office.

The NIMH Genetics Workgroup. (1998). Genetics and mental disorders (NIH Publication No. 98-4268). Rockville, MD: National Institute of Mental Health.

Tarrasch, R., Lurie, O., Yanovich, R., \& Moran, D. (2011). Psychological aspects of the integration of women into combat roles. Personality and Individual Differences 50, 305-309.

Riddle, J. R., Smith, T. C., Smith, B., Corbeil, T. E., Engel, C. C., Wells, T. S., et al. (2007) Millennium cohort: the 2001-2003 baseline prevalence of mental disorders in the U.S. military. Journal of Clinical Epidemiology, 60, 192-201.

Rothman, K., \& Greenland, S. (1998). Modern epidemiology (2nd ed.). Philadelphia, PA: Lippincott-Raven Publishers. 